\title{
Pore Scale Simulation of Colloid Deposition
}

\author{
M. Ekrem Cakmak1,2, Bin Gao ${ }^{3}$, John L. Nieber, and Tammo S. Steenhuis ${ }^{1}$ \\ ${ }^{1}$ Cornell University Ithaca, NY USA; ${ }^{2}$ Cukurova University, Adana, \\ ${ }^{3}$ University of Florida, Gainesville, FL, USA; ${ }^{4}$ University of Minnesota, St. Paul, MN \\ $1,3,4$ USA, ${ }^{2}$ Turkey
}

\section{Introduction}

Mobile subsurface colloids have received considerable attention because the migration of colloids and colloid-contaminant complexes through the solid matrix substantially increase the risk of groundwater pollution. Typically defined as suspended particulate matter with diameter less than $10 \mu \mathrm{m}$, colloids include both organic and inorganic materials such as microorganisms, humic substances, clay minerals and metal oxides. Accurate prediction of the fate of colloids is important to predict colloid facilitated transport of pollutants, and the transport of biocolloids such as viruses and bacteria.

In colloid transport studies colloid deposition, that is, the capture of colloids by grain surfaces, is considered as the primary mechanism controlling the transport of colloids in groundwater (Ryan \& Elimelech; 1996). The role of electrostatic and hydrodynamic forces in controlling colloid deposition behavior of colloids has been afforded detailed investigation in the field of colloid science to gain more understanding about colloid-surface interaction processes. The study of deposition rates of colloids onto model collectors has provided substantial information on the electrostatic and hydrodynamic forces involved in the transport of colloids (Elimelech et al., 1995; Tien \& Ramarao, 2007). Most of these studies have focused on colloid transport under saturated conditions (Yao et al., 1971; Rajagopalan \& Tien, 1976; Ryan \& Elimelech, 1996; Keller \& Auset, 2007). However, there is not much information available on colloid behavior under unsaturated conditions due to the complexity of the conditions involved (DeNovio et al., 2004; Keller \& Sirivithayapakorn, 2004; Auset \& Keller; 2004; Crist et al., 2005; Zevi et al., 2005; Keller \& Auset, 2007).

Most of the experimental and modeling studies on colloid transport under unsaturated conditions have focused primarily on colloid concentration in drainage water with very little emphasis on the precise mechanisms retaining the colloids in the pores (Corapcioglu \& Choi, 1996; Lenhart \& Saiers, 2002; DeNovio et al., 2004).

Generally, the approaches used to simulate colloid transport can be classified into two types, Lagrangian or Eulerian. The Lagrangian approach focuses on the movement of distinct particles and tracks particle position in a moving fluid (Rajagopalan \& Tien, 1976; Ryan and Elimelech, 1996). In contrast, the Eulerian approach considers the concentration distribution of particles in a porous media (Yao et al., 1971; Tufenkji \& Elimelech, 2004). The Eulerian approach has advantages over the Lagrangian approach, in that it does not require high computational performance, and it is easy to incorporate Brownian motion (Ryan and Elimelech, 1996; Nelson \& Ginn, 2005). 
The deposition of colloids in porous media has been investigated by several researchers to improve existing methods by incorporating the forces such as hydrodynamic and attractive forces into the governing equations (Yao et al., 1971; Rajagopalan \& Tien, 1976; Tufenkji \& Elimelech, 2004). For instance, Yao et al. (1971) developed colloid filtration theory as a method for predicting colloid deposition in saturated porous media. A limitation of these studies is that the colloid transport and deposition simulations have been performed only for saturated media consisting of clean and spherical solid grains (collectors). These limitations led us to find a method to simulate colloid transport under unsaturated conditions where the air phase comes into play in addition to solid grains and moving water. This may be partly accomplished by modifying existing methods developed for saturated conditions.

The main difficulty in more complex calculations is that the simulation methods are cumbersome, usually slow and cannot capture the complex pore geometries that exist in nature. That is why an effective, reliable, user-friendly and easy to be modified simulation software is very important and needed in the modeling and simulation studies.

The objective for this chapter is to illustrate a test of the suitability of a finite element based computational modeling and simulation software package named COMSOL Multiphysics ${ }^{\circledR}$ v33.a (COMSOL, Inc., Burlington, MA, USA), for simulating colloid deposition on solid grains and air bubbles for conditions where Brownian motion dominates.

In the first part of the chapter we compare the COMSOL finite element solution with the analytical solutions of Yao et al. (1971), Rajagopalan \& Tien (1976), and Tufenkji \& Elimelech (2004) of classical filtration theory for one grain of a porous media. The second part involves the simulation of colloid deposition onto an inert air bubble.

\section{Colloid Filtration Theory}

In colloid filtration theory, the deposition efficiency of a porous medium is represented by the deposition efficiency of a unit collector, i.e. an isolated solid grain (Yao et al., 1971; Ryan \& Elimelech, 1996; Tufenkji \& Elimelech, 2004). It is assumed that the porous medium is represented by an assemblage of perfect spherical solid grains (collectors). According to the theory, the transport of suspended colloids in the pore fluid to the vicinity of a stationary collector (i.e. a solid grain) is typically governed by three mechanisms: interception, gravitational settling, and Brownian diffusion. Interception takes place when the particles moving along the trajectories of flow streamlines come into contact with the collector due to the collector's finite size. Gravitational settling occurs when colloid particles have densities greater than the fluid density. These particles can then collide with a collector. The Brownian motion mechanism leads to diffusive migration of particles within a fluid and becomes significant for particles smaller than $1 \mu \mathrm{m}$.

The transport of colloids is usually simulated by solving the convection-diffusion equation using a velocity field for the pore space between grains simulated with the Navier-Stokes equation for creeping flow conditions. The deposition of colloids from the fluid occurs by transfer of the colloids from the moving pore fluid onto the grain surface by the three aforementioned mechanisms. It is assumed that colloids do not accumulate on the grain surface, but that colloids 'disappear' once they are intercepted by the grain. The rate of overall particle deposition is found by integrating the particle flux over the collector surface. Within filtration theory it is also common to assume no colloid-colloid interaction, and that colloids do not affect the fluid flow. 
The deposition of colloids onto a single grain has been simulated by Yao et al. (1971), Rajagopalan \& Tien (1976) and Tufenkji \& Elimelech (2004). Yao et al. (1971) developed an equation to find the deposition efficiency of a unit collector by analytically solving the convection-diffusion equation based on the additivity assumption that allows the addition of the analytical solutions of each deposition mechanisms (interception, gravitational settling, and Brownian diffusion) independently (Nelson \& Ginn, 2005). They assumed that the collector existed in an infinite fluid stream with no interaction from surrounding collectors. For the same problem, Rajagopalan and Tien (1976) used the Lagrangian approach, (i.e., particle trajectory analysis) with boundary conditions for the flow field similar to Happel (1958). These boundary conditions took into account the neighboring collectors as if the single (simulated) grain was located in a real porous media. Finally, Tufenkji and Elimelech (2004) developed a closed-form solution for calculating colloid deposition efficiency of a solid grain by combining the approaches of Yao et al. (1971) and Rajagopalan \& Tien (1976).

\section{Simulation Methodology}

Since in addition to gravity effects, Brownian movement of colloids is of particular interest in the work presented here, the Eulerian colloid filtration theory originally developed by Yao et al. (1971) is chosen in our simulations. In this manuscript, the deposition of colloids on a single collector is simulated for the same boundary conditions as Rajagopalan and Tien (1976). To find the velocity field the Navier-Stokes equations are solved with the finite element method. The resulting velocity field is then used in the solution to the convectiondiffusion equation, with diffusion being due to Brownian motion of colloids and with gravitational settling included. In the next sections, the Navier-Stokes equation and the convection-diffusion equations are discussed both in general, and specifically how they are used in our simulations.

\subsection{Navier-Stokes Equation}

The Navier-Stokes equations are employed to represent steady state creeping incompressible flow conditions, i.e.

$$
\begin{gathered}
-\frac{\partial p}{\partial i}+\mu \cdot \nabla^{2} v_{i}+\rho_{w} g_{i}=0 \quad i=x, y, z \\
\nabla \cdot \underline{v}=0
\end{gathered}
$$

where $p$ is the pressure (Pa), $\mu$ is the dynamic viscosity of the water (Pa.s), $v_{x}, v_{y}, v_{z}$ are the vector components for the velocity $\left(\underline{v}=v_{x} \vec{i}+v_{y} \vec{j}+v_{z} \vec{k}\right)$ of the water $(\mathrm{m} / \mathrm{s}), \quad \rho_{w}$ is the density of the water $\left(\mathrm{kg} / \mathrm{m}^{3}\right)$, and $g_{x}, g_{y}, g_{z}$ are the vector components for the gravitational acceleration $\left(9.81 \mathrm{~m} / \mathrm{s}^{2}\right)$. Equation (1) is valid for Reynolds number much less than one. The Reynolds number is defined as

$$
R_{e}=\frac{\underline{v} d \rho_{w}}{\mu}
$$

where $d$ is the diameter of the collector $(\mathrm{m})$. 
In a porous medium, fluid flow around a spherical collector is affected by the presence of other collectors around it. Therefore, a proper flow model for porous media is needed to reflect the disturbance of the flow field around the individual collectors. Among the various theoretical models Happel's fluid shell model is the most commonly used model (Elimelech, 1994; Tien \& Ramarao, 2007). Though the effect of neighboring collectors on fluid flow around the isolated unit collector is neglected in the original colloid filtration theory (Yao et al., 1971), it is considered in this chapter by adopting Happel's model.

In Happel's model, the porous medium is constructed of identical spherical collectors, each of which is in a fluid shell (Fig. 1). In order to maintain the overall porosity of the porous medium for a single collector, the thickness of the shell, $b$, is defined as

$$
b=d(1-\varepsilon)^{-1 / 3}
$$

where $\varepsilon$ is the porosity of the porous medium.

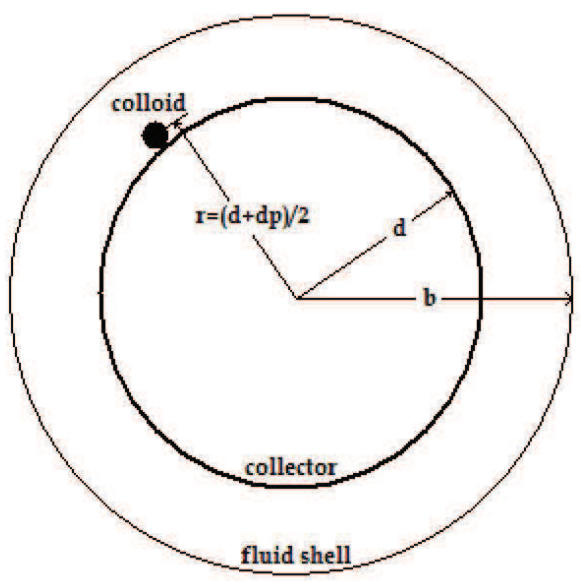

Figure 1. Schematic representation of a unit collector, and Happel's fluid shell

The boundary conditions used in our simulations in the solution of the Navier-Stokes equations can be summarized as follows. The surface of the fluid shell is specified as a symmetry boundary to take the effect of neighboring collectors on fluid flow into account. The symmetry boundary means that the velocity of the water normal to the boundary is zero at that boundary, and that the tangential component of the viscous force vanishes. A no-slip boundary condition is specified at the surface of the solid grain where the water velocity equals zero (Spielman, 1977; Tien \& Ramarao, 2007). Later we will consider the simulations for flow around a single air bubble, and for that case the surface of the bubble is specified to be a slip boundary (Nguyen \& Jameson, 2005; Shew \& Pinton, 2006).

\subsection{Convection-Diffusion Equation}

Once the velocity field is determined, the distribution of colloids within the pore space of a porous medium can be found by solving the convection-diffusion equation for steady state conditions (Yao et al., 1971). The convection-diffusion equation is given by 


$$
[\underline{v} \cdot \nabla C]-\left[D \cdot \nabla^{2} C\right]-\sum_{i}\left[\left(1-\frac{\rho_{w}}{\rho_{p}}\right) \frac{m g_{i}}{3 \pi \mu d_{p}} \frac{\partial C}{\partial x_{i}}\right]=0
$$

where $C$ is the concentration of the colloids (number of colloids $/ \mathrm{m}^{3}$ ), $D$ is the diffusion coefficient of the colloids calculated by Einstein's equation (Equation 9) $\left(\mathrm{m}^{2} / \mathrm{s}\right), \rho_{p}$ is the density of an individual colloid $\left(\mathrm{kg} / \mathrm{m}^{3}\right), m$ is the mass of the colloids $(\mathrm{kg})$, and $d_{p}$ is the diameter of the colloids $(\mathrm{m})$. The terms in the equation represent (left to right) the colloid transport processes of convection, diffusion, and gravitational settling.

When colloids make contact with a collector surface it is assumed that they disappear into the collector by specifying the collector surface as being a perfect sink. This means that all colloids arriving at the collector surface are irreversibly captured. The condition for a perfect sink can be achieved by setting the concentration in the vicinity of the collector surface to zero, i.e.,

$$
\mathrm{C}=0 \text { at } \mathrm{r}=\left(\mathrm{d}+\mathrm{d}_{\mathrm{p}}\right) / 2
$$

where $r$ represents the radius of an imaginary spherical surface displaced slightly outward from the surface of the collector (m) (Fig. 3.1).

At an infinite distance from the collector center the colloid concentration is assumed to be equal to the free stream concentration, $C_{0}$ (Yao et al., 1971; Elimelech, 1994).

$$
\mathrm{C}=\mathrm{C}_{0} \text { at } \mathrm{r}=\infty
$$

In previous analyses that used Happel's model for the flow velocity field, the above boundary condition is specified at the surface of the fluid shell, i.e.,

$$
\mathrm{C}=\mathrm{C}_{0} \text { at } \mathrm{r}=\mathrm{b}
$$

The diffusion coefficient in the convection-diffusion equation is calculated by Einstein's equation

$$
\mathrm{D}=\mathrm{kT} / 3 \pi \mu \mathrm{d}_{\mathrm{p}}
$$

where $k$ is the Boltzmann's constant $\left(1.380650310^{-23} \mathrm{~J} / \mathrm{K}\right)$, and $T$ is the absolute temperature (Kelvin).

\subsection{Deposition (Collision) Efficiency}

Solution of equations (1), (2) and (5) subject to the corresponding boundary conditions will yield the mass of particles entering the shell, the concentration of particles within the spherical shell, and the mass of particles leaving the shell. Also, the flux of particles passing into the ideal sink will also be determined from that solution. The solution can then be used to determine the particle deposition efficiency, $\eta$, which is calculated as

$$
\eta=\frac{I}{v_{0} C_{0} \frac{\pi d_{p}^{2}}{4}}
$$

where $I$ is the total particle deposition rate onto a collector, obtained by integrating the particle flux over the surface of the collector, $v_{0}$ is the free stream (initial) water velocity $(\mathrm{m} / \mathrm{s}$ ) (Yao et al., 1971; Tufenkji \& Elimelech, 2004). This integration can be done readily with COMSOL. 


\subsection{Numerical Solution}

A finite element based computational modeling and simulation software package, COMSOL Multiphysics ${ }^{\circledR}$ (COMSOL, Inc., Burlington, MA, USA), is chosen for simulating colloid deposition in this study due to its features that seemed to meet the above needs. This software is fast and reliable, allows creation of complex geometries, and the influences of boundary conditions can be assessed easily.

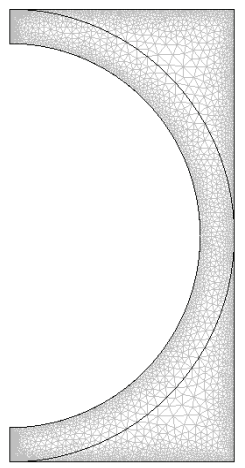

Figure 2. The mesh system used in this study

The simulations are performed, as in earlier studies (Yao et al., 1971; Rajagopalan \& Tien, 1976; Tufenkji \& Elimelech, 2004), in an axisymmetric domain that provides threedimensional results from two-dimensional simulations (Nelson et al., 2007).

Triangular elements are used in the mesh system (Fig. 2). The number of elements in the mesh system used in the simulations is determined by trial and error. The number of elements is increased until the results do not vary substantially. By default COMSOL generates mesh systems automatically. In our case with a sub-domain that has a high aspect ratio due to the boundary condition specified by Equation 6, better results were obtained when the mesh system was created in part by manual specification of mesh generation parameters.

Once the mesh system was established the simulations were performed with colloid diameters varying from 0.05 to $2 \mu \mathrm{m}$, and a constant collector diameter of $0.6 \mathrm{~mm}$ as described in more detail in the next section.

\section{Simulations: Setup and Results}

\subsection{Colloid Deposition on a Grain Collector}

In this section, the colloid deposition efficiency of a spherical solid grain (collector) is simulated numerically using COMSOL. The results are compared with three previous studies (Yao et al., 1971; Rajagopalan \& Tien, 1976; Tufenkji \& Elimelech, 2004).

The boundary conditions for the solution of the Navier-Stokes equation are summarized in Table 1 and shown graphically in Fig. 3. Flow direction and gravity are both opposite to the direction of the y-axis. The convection-diffusion equation is solved with the same boundary conditions as in Yao et al. (1971) except that, the colloid concentration at the fluid shell surface is set to be equal to the initial concentration (Equation 8), while Yao et al. (1971) assumed the concentration to be equal to the initial concentration at an infinite distance from the collector surface (Equation 7). 


\begin{tabular}{|l|l|}
\hline Boundary & Condition \\
\hline Inlet & $v_{0}=9 \times 10^{-6} \mathrm{~m} / \mathrm{s}$ \\
\hline Collector Surface & No-slip $(v=0 \mathrm{~m} / \mathrm{s})$ \\
\hline Outlet & Pressure $(0 \mathrm{~Pa})$ \\
\hline Sides, Fluid Shell & Symmetry \\
\hline
\end{tabular}

Table 1. The boundary conditions used to solve the Navier-Stokes equation for a solid grain

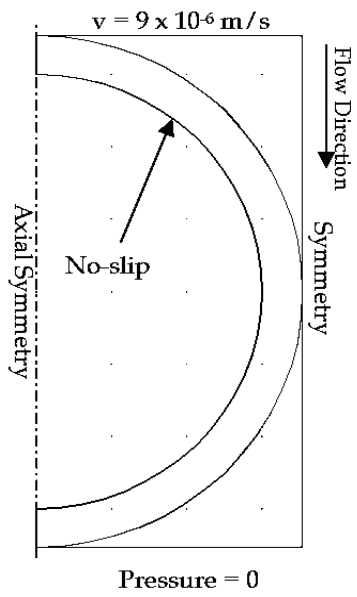

Figure 3. The boundary conditions for the Navier-Stokes Equation (solid grain)

In order to compare our results with the previous studies, the parameter values used in the simulations were adopted from the study of Tufenkji \& Elimelech (2004) (Table 2). Simulations were performed for colloids with diameters of $0.05,0.10,0.50,0.75,1,1.5$, and 2 $\mu \mathrm{m}$ and a grain diameter of $0.6 \mathrm{~mm}$. The most time-consuming step in our simulations was the trial and error generation of the mesh. Once the optimum mesh system was found, each simulation took an average of 37 seconds.

\begin{tabular}{|c|c|l|}
\hline \multicolumn{2}{|c|}{ Variable } & Value \\
\hline$d$ & Collector diameter & $0.6 \mathrm{~mm}$ \\
\hline$v_{0}$ & Initial water velocity & $9 \times 10^{-6} \mathrm{~m} / \mathrm{s}$ \\
\hline$T$ & Temperature & $288 \mathrm{~K}$ \\
\hline$k$ & Boltzmann constant & $1.380650310^{-23} \mathrm{~J} / \mathrm{K}$ \\
\hline$\varepsilon$ & Porosity & 0.39 \\
\hline$\rho_{w}$ & Density of water & $1000 \mathrm{~kg} / \mathrm{m} 3$ \\
\hline$\rho_{p}$ & Density of colloids & $1050 \mathrm{~kg} / \mathrm{m} 3$ \\
\hline$\mu$ & Dynamic viscosity of water & $0.001 \mathrm{~Pa} . \mathrm{s}$ \\
\hline
\end{tabular}

Table 2. Variables used in the simulations (Tufenkji \& Elimelech, 2004).

The simulation results are given in Fig. 4 together with the results of the three other studies (Yao et al., 1971; Rajagopalan \& Tien, 1976; Tufenkji \& Elimelech, 2004). Similar to the other studies, colloid deposition efficiency is the greatest for the $0.05 \mu \mathrm{m}$ colloids than decreases with larger colloids diameter. When colloid diameters are on the order of $1 \mu \mathrm{m}$ colloid deposition increases again (Fig. 4). 
The integration of the particle flux on the zero concentration boundary (Equation 6) reveals that the diffusion as well plays an important role in the increased collection efficiency because the ratio of the colloid efficiencies is not the same for the different colloid diameters.

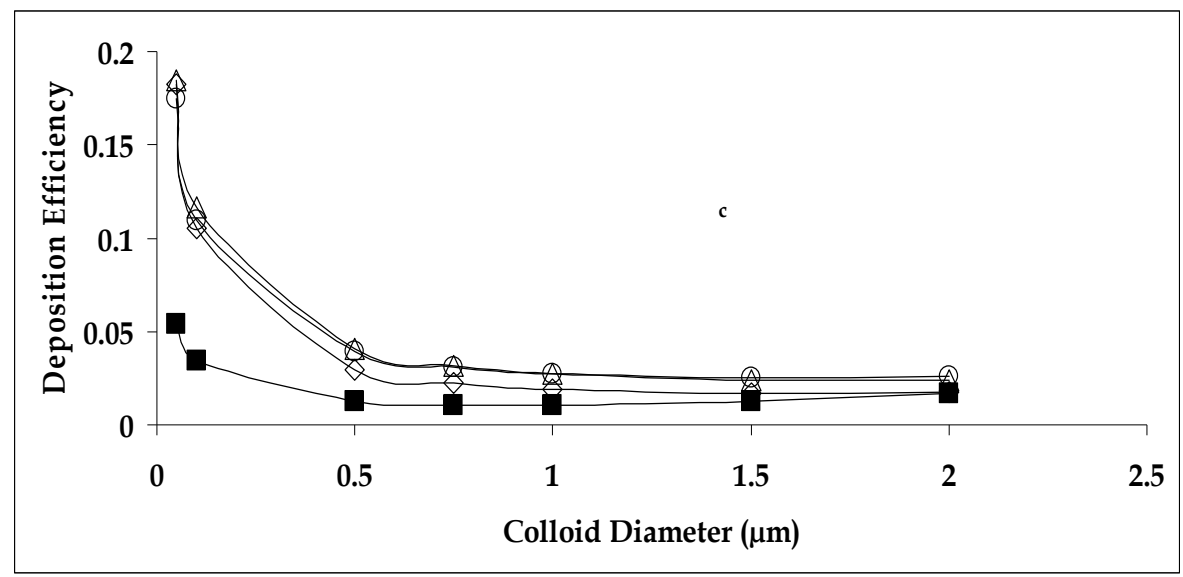

Figure 4. Deposition efficiency of a single collector vs. colloid size (diameter)

$(\triangle)$ Rajagopalan \& Tien, $1976(\diamond)$ Tufenkji \& Elimelech, 2004 (घ) Yao et al., 1971 (○) Result of the current analysis

A comparison of our simulated deposition efficiency with those of the other three studies is presented in Fig. 4. It is observed that our results agree very well with the Rajagopalan \& Tien (1976) results. The worst comparison is with the result of Yao et al. (1971), while an intermediate agreement is achieved with the results of Tufenkji \& Elimelech (2004). One reason why our results are so different from the results of Yao et al. (1971) is that they did not incorporate the boundary effect of neighboring collectors into their solution. Another possible reason for the difference is that the efficiency calculations made by Yao et al. (1971) were based on the additivity assumption. While this assumption simplifies the solution, it could be problematic as noted by Nelson \& Ginn (2005). We do not yet know why our solution results disagree with those of Tufenkji and Elimelech (2004).

\subsection{Colloid Deposition on an Air Bubble Collector}

In this simulation of colloid deposition efficiency, the only change made was replacing the grain with an air bubble of the same size. For the numerical simulation this means that the no slip boundary becomes a slip boundary condition at the collector surface while the remaining parameter values and grid remain the same (Table 3 and Fig. 5). The slip boundary has been used before for rising air bubbles in fluids by Nguyen \& Jameson (2005) and Shew \& Pinton (2006).

\begin{tabular}{|l|l|}
\hline Boundary & Condition \\
\hline Inlet & $v_{0}=9 \times 10^{-6} \mathrm{~m} / \mathrm{s}$ \\
\hline Collector Surface & Slip $(v \neq 0 \mathrm{~m} / \mathrm{s})$ \\
\hline Outlet & Pressure $(0 \mathrm{~Pa})$ \\
\hline Sides, Fluid Shell & Symmetry \\
\hline
\end{tabular}

Table 3. The boundary conditions used to solve the Navier-Stokes equation for air bubble 


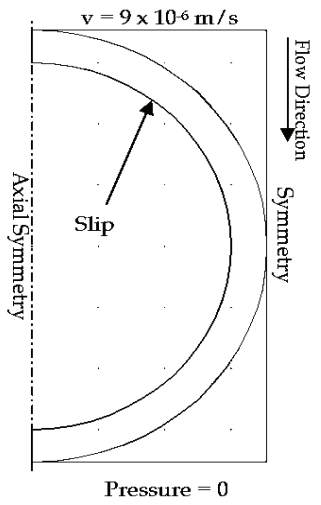

Figure 5. The boundary conditions for the Navier-Stokes Equation (air bubble)

The results of the simulation with the air bubble collector are compared to those for the solid particle in Fig. 6. It is observed that the deposition efficiency of the air bubble is approximately twice that of the solid grain. The effects of the no-slip and slip boundaries on the water flow velocities are illustrated in Fig. 7. The water velocity around the air bubble is greater than the water velocity around the solid grain because under laminar flow conditions, the water (and thus the colloid velocity) approaches zero near the grain surface.

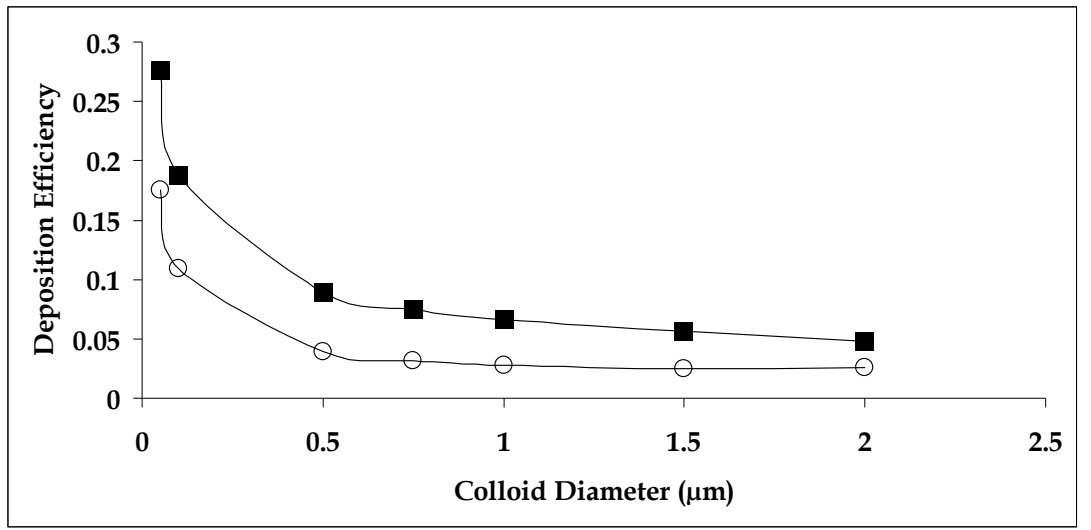

Figure 6. Deposition efficiency of the collectors vs. colloid size (diameter) (๘) Air Bubble (०) Solid Grain

The differences between the two cases are due to the relative fraction of colloids that come into the vicinity of the diffusion boundary. Regions of high velocity will transport a larger fraction of colloids in contrast to regions of low velocity. For the case of the bubble, the slip boundary results in high water velocity near the diffusion boundary and therefore a relatively high fraction of colloids will be transported in the vicinity of that boundary, resulting in higher concentration gradients at the diffusion boundary. For the case of the solid particle, the no-slip boundary results in a lower velocity near the diffusion boundary and therefore a relatively lower fraction of colloids will be transported in the vicinity of the diffusion boundary, resulting in lower concentration gradients at that boundary. That the 
difference between the two cases decreases as the particle size increases can be explained by fact that as the colloid diffusion decreases (with increasing diameter) the differences in transport across the diffusion boundary will also decrease. As the diffusion becomes vanishingly small, the colloid concentrations at the diffusion boundary will be identical for the two cases, exactly equal to the initial concentration, $C_{0}$.

While various surface forces (capillary, DLVO, electrostratic, etc.) were not considered in our analysis, the differences in flow velocity near the collector surface between the solid collector and the air bubble are expected to have significant influence on the predicted efficiency of colloid deposition when such forces are incorporated into the governing transport equations (Wan \& Tokunaga, 2002; Zevi et al., 2005; Elimelech et al., 1995; Tien \& Ramarao, 2007).

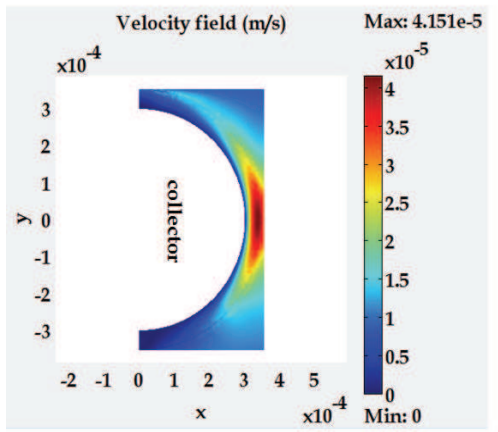

a) Solid Grain (No-Slip Boundary)

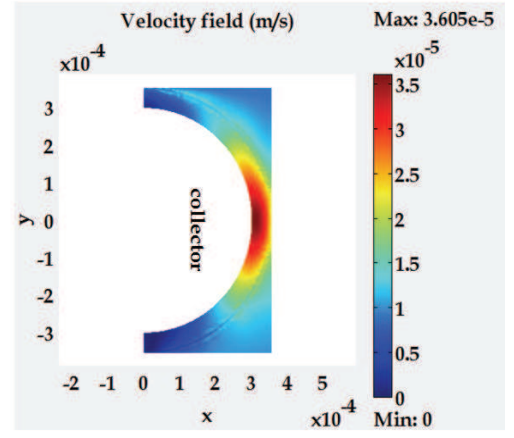

b) Air Bubble (Slip Boundary)

Figure 7. Velocity fields around the collectors

\section{Conclusions}

The re-examination of the colloid filtration theory revealed that it is crucial to consider the effect of surrounding solid grains on the flow field in order to gain more realistic results. The application of the colloid filtration theory on the air bubble showed that more colloids collided with the air bubble than with the solid grain due to high pore water velocity around its surface. The pore water velocity and the disturbances in the flow field have a substantial effect on the deposition and transport paths of the colloids. Nevertheless, in order to thoroughly examine the effect of pore water velocity on the dominant deposition mechanism, the simulations should be done with various initial water velocities. To better model an unsaturated porous medium, simulations with assemblages of collectors need to be performed.

\section{Future Work}

Our simulations of the colloid deposition in unsaturated porous media need to be extended to take domains composed of assemblages of collectors into account. We are interested to study the variables/parameters that will affect the colloid deposition.

It is planned to construct a model porous medium consisting of solid grains and air bubbles in two dimensions and three dimensions. This is expected to provide more insight into the colloid deposition for unsaturated conditions. This is partially done and sample simulations are shown in Fig. 8. 

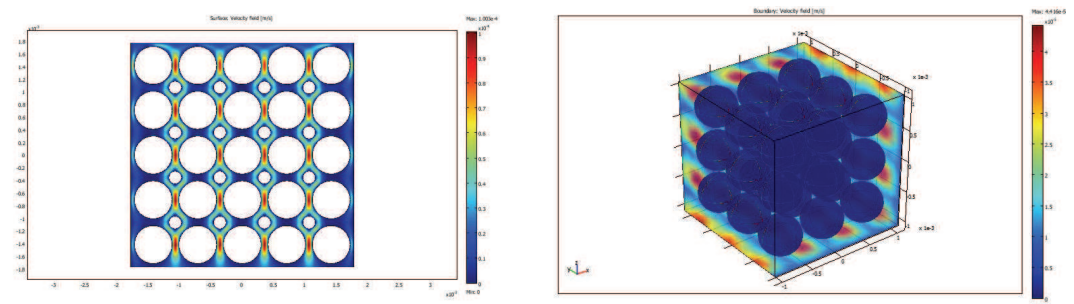

Figure 8. Future simulations to be performed for 2-D and 3-D domains

\section{Nomenclature}

C: Concentration of the colloids (number of colloids $/ \mathrm{m}^{3}$ )

$C_{0}$ : Initial (free stream) concentration of colloids (number of colloids $/ \mathrm{m}^{3}$ )

$b$ : Thickness of Happel's fluid shell (m)

$d$ : Diameter of a unit collector (i.e. air bubble or solid grain) (m)

$d_{p}$ : Diameter of colloids $(\mathrm{m})$

$D:$ Diffusion coefficient $\left(\mathrm{m}^{2} / \mathrm{s}\right)$

$g_{i}$ : Components of gravitational acceleration $\left(g_{x}, g_{y}, g_{z}\right)\left(9.81 \mathrm{~m} / \mathrm{s}^{2}\right)$ in the $x, y$ and $z$ coordinate directions

I: Total colloid deposition rate onto a collector

$k$ : Boltzmann's constant $(\mathrm{J} / \mathrm{K})$

$m$ : Mass of the colloids $(\mathrm{kg})$

$p$ : Pressure $(\mathrm{Pa})$

$r$ : The radius of an imaginary spherical surface displaced slightly outward from the surface of the collector $(\mathrm{m})$

$R_{e}:$ Reynolds number

T: Absolute temperature (Kelvin)

$\underline{v}=v_{x} \vec{i}+v_{y} \vec{j}+v_{z} \vec{k}$ : Resultant velocity (m/s), with $v_{x}, v_{y}$ and $v_{z}$ being velocity components in

the $x, y$ and $z$ coordinate directions, respectively

$v_{0}$ : Free stream (initial) water velocity $(\mathrm{m} / \mathrm{s})$

$\varepsilon$ : Porosity of porous medium

$\mu$ : Dynamic viscosity of water (Pa.s)

$\rho_{w}$ : Density of water $\left(\mathrm{kg} / \mathrm{m}^{3}\right)$

$\rho_{p}$ : Density of an individual colloid $\left(\mathrm{kg} / \mathrm{m}^{3}\right)$

$\eta$ : The particle deposition efficiency

\section{References}

Auset, M. \& Keller, A. A. (2004). Pore-scale processes that control dispersion of biocolloids in saturated porous media. Water Resour Res, 40, 3, (Mar 2004) W03503, ISSN: 0043-1397.

Corapcioglu, M. Y. \& Choi, H. (1996). Modeling colloid transport in unsaturated porous media and validation with laboratory column data. Water Resour Res, 32, 12, (Dec 1996) 3437- 3449, ISSN: 0043-1397.

Crist, J. T.; Zevi, Y.; McCarthy, J. F.; Throop, J. A. \& Steenhuis, T. S. (2005). Transport and retention mechanisms of colloids in partially saturated porous media. Vadose Zone J, 4, 1, (Feb 2005) 184- 195, ISSN: 1539-1663. 
DeNovio, N. M.; Saiers, J. E. \& Ryan, J. N. (2004). Colloid movement in unsaturated porous media: Recent advances and future directions. Vadose Zone J, 3, 2, (May 2004) 338-351, ISSN: 1539-1663.

Elimelech, M. (1994). Particle deposition on ideal collectors from dilute flowing suspensions: mathematical formulation, numerical solution, and simulations. Sep Technol, 4, 4, (Oct 1994) 186-212, ISSN: 0956-9618.

Elimelech, M.; Gregory, J.; Jia, X. \& Williams, R. A. (1995). Particle deposition and aggregation: measurement, modelling, and simulation, Butterworth-Heinemann, ISBN:075067024X, Oxford, England.

Happel, J. (1958). Viscous flow in multiparticle systems: slow motion of fluids relative to beds of spherical particles. AIChE J, 4, 2, 197-201, ISSN: 0001-1541.

Keller, A. A. \& Auset, M. (2007). A review of visualization techniques of biocolloid transport processes at the pore scale under saturated and unsaturated conditions. Advances in Water Resour, 30, 6-7, (Jun-Jul 2007) 1392-1407, ISSN: 0309-1708.

Keller, A. A. \& Sirivithayapakorn, S. (2004). Transport of colloids in unsaturated porous media: Explaining large-scale behavior based on pore scale mechanisms. Water Resour Res, 40, 12, (Dec 2004) W12403, ISSN: 0043-1397.

Lenhart, J. J. \& Saiers, J. E. (2002). Transport of silica colloids through unsaturated porous media: Experimental results and model comparisons. Environ Sci Technol, 36, 4, (Feb 2002) 769-777, ISSN: 0013-936X.

Nelson, K. E.; Massoudieh, A. \& Ginn, T. R. (2007). E. coli fate and transport in the Happel spherein-cell model. Advances in Water Resour, 30, 6-7, (Jun-Jul 2007) 1492-1504, ISSN: 0309-1708.

Nelson, K. E.; Massoudieh, A. \& Ginn, T. R. (2007). E. coli fate and transport in the Happel sphere-in-cell model. Advances in Water Resour, 30, 6-71492-1504, ISSN: 0309-1708.

Nguyen, A. V. \& Jameson, G. J. (2005). Sliding of fine particles on the slip surface of rising gas bubbles: Resistance of liquid shear flows. International Journal of Multiphase Flow, 31, 4, (Apr 2005) 492-513, ISSN: 0301-9322.

Rajagopalan, R. \& Tien, C. (1976). Trajectory analysis of deep-bed filtration with the sphere-incell porous media model. AIChE J, 22, 3, (May 1976) 523-533, ISSN: 0001-1541.

Ryan, J. N. \& Elimelech, M. (1996). Colloid mobilization and transport in groundwater. Colloid Surf A, 107, (Feb 1996) 1-56, ISSN: 0927-7757.

Shew, W. L. \& Pinton, J. F. (2006). Viscoelastic effects on the dynamics of a rising bubble. J Stat Mech, (Jan 2006) P01009, ISSN: 1742-5468.

Spielman, L. A. (1977). Particle capture from low-speed laminar flows. Annual Review Of Fluid Mechanics, 9, 297-319, ISSN: 0066-4189.

Tien, C. \& Ramarao, B. V. (2007). Granular filtration of aerosols and hydrosols, ButterworthHeinemann, ISBN:9781856174589, Great Britain.

Tufenkji, N. \& Elimelech, M. (2004). Correlation equation for predicting single collector efficiency in physicochemical filtration in saturated porous media. Environ Sci Technol, 38, 2, (Jan 2004) 529-536, ISSN: 0013-936X.

Yao, K. M.; Habibian, M. T. \& O'Melia, C. R. (1971). Water and waste water filtration: concepts and applications, Environ Sci Technol, 5, 11, (Nov 1971), 1105-1112, ISSN: 0013-936X.

Zevi, Y.; Dathe, A., McCarthy, J. F.; Richards, B. K. \& Steenhuis, T. S. (2005). Distribution of colloid particles onto interfaces in partially saturated sand. Environ Sci Technol, 39, 18, (Sep 2005) 7055- 7064, ISSN: 0013-936X. 


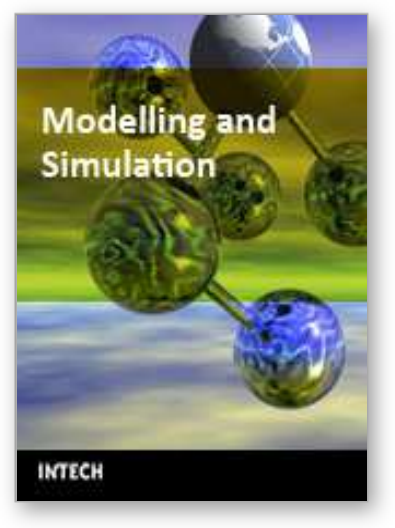

\author{
Modelling and Simulation \\ Edited by Giuseppe Petrone and Giuliano Cammarata
}

ISBN 978-3-902613-25-7

Hard cover, 688 pages

Publisher I-Tech Education and Publishing

Published online 01, June, 2008

Published in print edition June, 2008

This book collects original and innovative research studies concerning modeling and simulation of physical systems in a very wide range of applications, encompassing micro-electro-mechanical systems, measurement instrumentations, catalytic reactors, biomechanical applications, biological and chemical sensors, magnetosensitive materials, silicon photonic devices, electronic devices, optical fibers, electro-microfluidic systems, composite materials, fuel cells, indoor air-conditioning systems, active magnetic levitation systems and more. Some of the most recent numerical techniques, as well as some of the software among the most accurate and sophisticated in treating complex systems, are applied in order to exhaustively contribute in knowledge advances.

\title{
How to reference
}

In order to correctly reference this scholarly work, feel free to copy and paste the following:

M. Ekrem Cakmak, Bin Gao, John L. Nieber and Tammo S. Steenhuis (2008). Pore Scale Simulation of Colloid Deposition, Modelling and Simulation, Giuseppe Petrone and Giuliano Cammarata (Ed.), ISBN: 978-3-90261325-7, InTech, Available from:

http://www.intechopen.com/books/modelling_and_simulation/pore_scale_simulation_of_colloid_deposition

\section{INTECH}

open science | open minds

\section{InTech Europe}

University Campus STeP Ri

Slavka Krautzeka 83/A

51000 Rijeka, Croatia

Phone: +385 (51) 770447

Fax: +385 (51) 686166

www.intechopen.com

\section{InTech China}

Unit 405, Office Block, Hotel Equatorial Shanghai

No.65, Yan An Road (West), Shanghai, 200040, China

中国上海市延安西路65号上海国际贵都大饭店办公楼 405 单元

Phone: +86-21-62489820

Fax: +86-21-62489821 
(C) 2008 The Author(s). Licensee IntechOpen. This chapter is distributed under the terms of the Creative Commons Attribution-NonCommercialShareAlike-3.0 License, which permits use, distribution and reproduction for non-commercial purposes, provided the original is properly cited and derivative works building on this content are distributed under the same license. 